
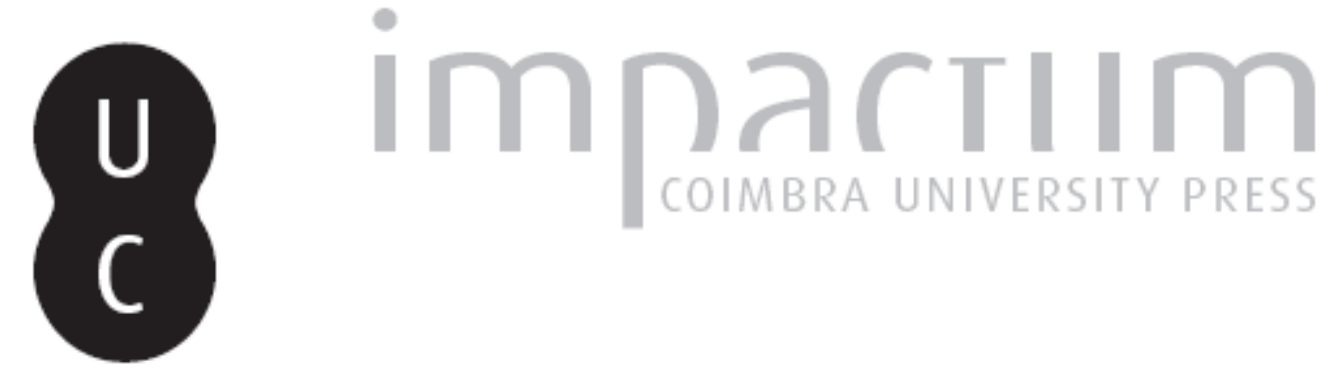

\title{
O Partido Socialista e as Europeias de 2014
}

\section{Autor(es): $\quad$ Frederico, Rui}
Publicado por: Centro de Informação Europe Direct de Aveiro; Centro de Estudos Interdisciplinares do Século XX

URL

persistente:

URI:http://hdl.handle.net/10316.2/39343

DOI:

DOI:http://dx.doi.org/10.14195/1647-6336_13_12

Accessed : $\quad$ 26-Apr-2023 16:15:02

A navegação consulta e descarregamento dos títulos inseridos nas Bibliotecas Digitais UC Digitalis, UC Pombalina e UC Impactum, pressupõem a aceitação plena e sem reservas dos Termos e Condições de Uso destas Bibliotecas Digitais, disponíveis em https://digitalis.uc.pt/pt-pt/termos.

Conforme exposto nos referidos Termos e Condições de Uso, o descarregamento de títulos de acesso restrito requer uma licença válida de autorização devendo o utilizador aceder ao(s) documento(s) a partir de um endereço de IP da instituição detentora da supramencionada licença.

Ao utilizador é apenas permitido o descarregamento para uso pessoal, pelo que o emprego do(s) título(s) descarregado(s) para outro fim, designadamente comercial, carece de autorização do respetivo autor ou editor da obra.

Na medida em que todas as obras da UC Digitalis se encontram protegidas pelo Código do Direito de Autor e Direitos Conexos e demais legislação aplicável, toda a cópia, parcial ou total, deste documento, nos casos em que é legalmente admitida, deverá conter ou fazer-se acompanhar por este aviso.

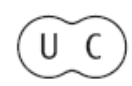


DEBATER

A EUROPA

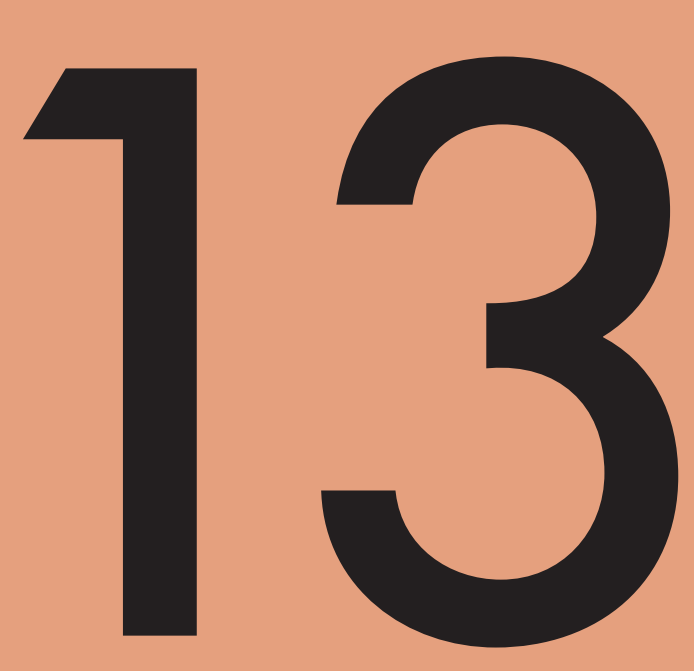

jul-dez 2015
A (DES) CONSTRUÇÃO DA EUROPA
(1939-1945)
(DE) CONSTRUCTING EUROPE (1939-1945) 


\title{
O Partido Socialista e as Europeias de 2014
}

Rui Frederico

IHC-UNL

E-mail: rui-frederico@ hotmail.com

\begin{abstract}
We would like to purpose a debate concerning the Portuguese Socialist Party thoughts and main doutrines about the Europe and European union integration of Portugal since Mario Soares until today. We thing this is one of the most important contributes the party gave to the Portuguese politics and it means that there is no debate about European Union without a reflexion related with the intervention and the action this political family gave to the project of Adenauer, Schumann and Monet for a better and a prosperous Europe.
\end{abstract}

Keywords: Socialist Party; European Union; Left; European

\section{Resumo}

Neste texto pretende-se desenvolver uma breve reflexão analítica em torno de conceitos, conteúdos programáticos, estratégias e definições doutrinárias de um dos quatro partidos estruturantes do regime democrático português relativamente à adesão do país à - à época - Comunidade Económica Europeia (hoje União Europeia), ao projeto comunitário, à abordagem às eleições europeias de 2014 - em concreto - e ao aprofundamento político, económico e monetário da integração e da UE 28. Nesta análise propomo-nos realizar uma retrospetiva histórica e sintética em torno dos fundamentos doutrinários e ideológicos do PS no que concerne à Europa no sentido de compreendermos algumas das realidades atuais dos socialistas nas eleições para o Parlamento Europeu de 2014. Observamos as atuais perspetivas europeias de alguns dos mais marcantes líderes socialistas, de Mário Soares a António José Seguro, passando por Jorge Sampaio ou Ferro Rodrigues, e as circunstâncias particulares que caracterizam o processo eleitoral. Procuramos fundamentos, fundações e bases que expliquem as 
estratégias utilizadas pelo PS para superar a coligação e direita constituída pelo PSD e o CDS. Procuramos enquadrar os resultados de 2014 numa perspetiva mais ampla que percorre as lideranças e a própria história europeia do partido.

Palavras-chave: Partido Socialista; União Europeia; Esquerda; Europeias

Perante um cenário de eleições europeias de importância primordial para o Partido Socialista, propomos uma breve reflexão analítica em torno de conceitos/conteúdos e algumas definições doutrinárias de um dos quatro partidos estruturantes do regime democrático português relativamente à adesão do país à Comunidade Económica Europeia (União Europeia) e à forma como abordou a campanha eleitoral de 2014 em concreto. Esta brevíssima análise e retrospetiva histórica, relativamente aos fundamentos doutrinários e ideológicos do PS no que concerne à Europa, pretende estabelecer uma ligação teórica entre as realidades políticas atuais, estratégicas, táticas e conceptuais dos socialistas - nas eleições para o Parlamento Europeu de 2014 - e as circunstâncias fundacionais do partido.

\section{Antes das Europeias de 2014}

A primeira circunstância de o Partido Socialista Português ter sido fundado na Alemanha em 1973 reflete de alguma forma - num quadro subjetivo e teórico de perspetivas e tendências individuais -, nas suas fundações, um enquadramento de partida que poderemos associar direta e objetivamente à vocação europeísta das suas linhas doutrinárias e dos seus principais conceitos no que diz respeito ao projeto de ideal comunitário. Poder-se-á igualmente relevar, neste seguimento, que as experiências individuais de alguns dos seus membros - como por exemplo Mário Soares -, ligadas à resistência e ao exílio, permitiriam o estabelecimento e a consolidação de uma relação estreita com partidos de tradição socialista e federalizante no espaço europeu e a formação de um pensamento político atento à realidade de uma Europa que caminhava nos idos 70 no sentido do alargamento que se verificaria ao longo da década de 80 e das posteriores. Não se refere que o facto de o PS ter sido fundado na Alemanha, por si só, justifica o pensamento europeu dos socialistas portugueses. No entanto, os contactos aí estabelecidos permitiriam ao partido a estruturação de redes doutrinárias e de ação política e, em particular, aos dirigentes um conhecimento mais profundo da realidade europeia e do pensamento dos grandes ideólogos da Europa. A década de 60 trouxera 
mudanças políticas que iriam sarando as feridas da Guerra e renovando a esperança num futuro próspero acalentada pelas repercussões do Tratado de Roma e a institucionalização da CEE, que cria a Política Agrícola Comum e abolirá as pautas aduaneiras ${ }^{1}$.

Os projetos e ideais de Adenauer, De Gasperi, Monnet e Shumann - os pais fundadores da "ideia europeia" -, no fundamental, de uma Europa construída em alicerces de paz e união progressiva, têm no Partido Socialista português um executante no terreno e nas instituições políticas nacionais e europeias, desde sempre, das suas principais linhas de pensamento, consideradas estruturantes e basilares do projeto de construção. Em 1964, em Genebra, já a Associação Socialista Portuguesa - organização de génese do partido criada na clandestinidade com militantes estabelecidos em várias partes da Europa - seria fundada em contexto europeu e em contato direto com as ideias trabalhistas e socialistas democráticas que eram geradas no centro dominante e os sistemas parlamentares vigentes no ocidente.

A declaração do bureau da Internacional Socialista, em 1969, sobre as eleições portuguesas, atesta essa génese cosmopolita e integradora do partido de Mário Soares que depois da revolução solicitaria o apoio europeu à transição e consolidação democráticas em Portugal no sentido também da edificação de uma muralha legal contra o internacionalismo marxista emergente. Mesmo antes da revolução do 25 de Abril de 1974 Mário Soares solicitara em 1971 aos partidos políticos congéneres europeus a admissão da Associação Socialista Portuguesa na Internacional Socialista, solicitação essa que viria a ser efetivamente apadrinhada por personalidades defensoras de uma Europa integrante e solidária, como Miterrand ou Pittermann. O pedido de adesão formal à CEE, em 1976, do Governo de Mário Soares, seria o corolário desta “inspiração e vocação" europeísta do partido herdeiro do republicanismo português. Membro da Internacional Socialista, desde a sua fundação, o Partido Socialista seria igualmente depois da integração na CEE, em 1986, enquadrado na família do Partido Socialista Europeu, o atual Grupo Parlamentar da Aliança Progressista dos Socialistas e Democratas no Parlamento Europeu, prova dos seus princípios fundacionais ligados à ideia de uma Europa "moderna, federal e humanista".

\footnotetext{
${ }^{1}$ SEBASTIÃO, Dina - Mário Soares e a Europa: Pensamento e Acção, dissertação de mestrado em História Contemporânea: economia, sociedade e relações internacionais. Coimbra: Universidade de Coimbra, 2010, p. 21.
} 
Considerado um partido "agrega-todos", o Partido Socialista interpretaria ao longo do seu historial as eleições europeias como uma extensão do seu pragmatismo internacionalista em liberdade, direcionando neste contexto singular alguns dos seus melhores quadros para as listas de deputados ao Parlamento Europeu como, por exemplo, em 2009, Vital Moreira, Edite Estrela, Capoulas Santos, Elisa Ferreira, Correia de Campos ou Ana Gomes, de acordo com uma lógica "paritária, progressista e aberta" relativamente ao número de candidatos homens e mulheres. Em disputa direta com outro partido estruturante do regime democrático português, o PPD/PSD, o PS alcançaria desde 1987 resultados que lhe permitiriam uma representação na Europa quer como segundo quer como primeiro partido português com maior número de deputados, i.e., os socialistas portugueses seriam também em contexto de políticas europeias um dos partidos mais influentes do sistema político, estatuto condizente com a sua condição de "partido do arco da governabilidade" e de poder.

Como podemos observar no quadro que se segue, os socialistas portugueses disputaram sempre com o PPD/PSD - que também por vezes surge em coligação com o CDS/PPP, como em 2014 - a liderança nas eleições europeias à semelhança dos contextos das eleições autárquicas e legislativas:

Quadro 1: Deputados ao PE (1987-2009)

\begin{tabular}{|c|c|c|c|c|}
\hline & Total & PS & PSD & PSD/CDS \\
\hline 1987 & 24 & 6 & 10 & - \\
\hline 1989 & 24 & 8 & 9 & - \\
\hline 1994 & 25 & 10 & 9 & - \\
\hline 1999 & 25 & 12 & 9 & - \\
\hline 2004 & 24 & 12 & - & 9 \\
\hline 2009 & 22 & 7 & 8 & - \\
\hline
\end{tabular}

Fonte: PORDATA

\footnotetext{
${ }^{2}$ A exemplo do PPD/PSD, o Partido Socialista afirmar-se-ia no sistema político como um partido vertical, integrador, interclassista e agregador no que concerne a simpatizantes, eleitores, aderentes e militantes. Colocado ao centro-esquerda, o Partido Socialista diferenciar-se-ia do PPD pela vocação mais socialdemocrata do que liberal, em oposição a uma matriz ideológica afastada do Estado, de centro-direita, desenhada nos conteúdos programáticos também pró-europeus do partido de Sá Carneiro e Francisco Pinto Balsemão.
} 
Mário Soares, de 1976 a 1978 e de 1983 a 1985, António Guterres, de 1995 a 2002 e José Sócrates, de 2005 a 2011, marcariam e reforçariam a matriz doutrinária federalizante do Partido Socialista, em relação à condução das suas diretrizes europeias, ao mesmo tempo que exerciam o cargo de Primeiro-ministro. Outras personalidades politicamente influentes, militantes ou independentes, como Jorge Sampaio, Ferro Rodrigues, Augusto Mateus, António Costa, Vitalino Canas, Carlos Zorrinho, Alberto Martins, José Junqueiro, o ex-centrista Basílio Horta ou Sérgio Sousa Pinto - antigo líder da Juventude Socialista e ex-deputado ao Parlamento Europeu - convergiriam no seio do partido no essencial no que concerne a questões como os Tratados de Maastricht, Lisboa, Nice ou Amesterdão, o pacto de estabilidade, a adesão ao Euro, o Tratado Orçamental e o aprofundamento do debate em torno de uma Europa a caminho da via de tendência "mais ou menos" federalizante e integradora.

Ao arrepio de outros partidos políticos - como o CDS/PP, por exemplo, em que cada líder tinha uma perspetiva ou mais federalista, como Freitas do Amaral, ou mais atlantista, como Adriano Moreira ou Manuel Monteiro -, o PS nas questões europeias defenderia ao longo da sua trajetória doutrinária as instituições, o aprofundamento, o modelo social europeu, a subsidiariedade e a participação dos povos europeus na condução dos destinos da União Europeia como elementos essenciais das definições estratégicas.

Mário Soares, de 1973 a 1986, Vítor Constâncio, de 1986 a 1989, Jorge Sampaio, de 1989 a 1992, António Guterres, de 1992 a 2002, Ferro Rodrigues, de 2002 a 2004, José Sócrates, de 2004 a 2011 e António José Seguro, desde 2011, assentariam as suas propostas europeias em linhas desenhadas, no essencial, de acordo com a família europeia a que o Partido Socialista pertence, sem divergências de fundo ou de contexto. Neste quadro, as eleições europeias funcionariam sempre como uma oportunidade para o Partido Socialista de difusão das suas perspetivas de vocação centralizadora dos poderes comunitários, federalizante e humanistas mas também, refira-se, das orientações do próprio diretório da família europeia a que pertence relativamente aos caminhos que o projeto de união deveria seguir.

Ao contrário do CDS/PP, por exemplo, o Partido Socialista nunca deixaria de fazer parte da sua família político-ideológica europeia de partida convergindo ao mesmo tempo na doutrina, nos conceitos e nos posicionamentos de fundo no sentido do aprofundamento do modelo social europeu, da "solidariedade europeia" e da igualdade de princípio entre os estados-membros. 
Numa Europa a 28, as eleições de Maio de 2014 realizar-se-iam num contexto particular dado o facto de o país atravessar a pior crise financeira e económica da III República e no quadro da "zona euro". Para o Partido Socialista, estas eleições justificaram todas as atenções uma vez que constituíam uma antecâmara das legislativas de 2015. O cabeça de lista do partido nas eleições de 2014, Francisco Assis, neste contexto, procuraria personificar e ao mesmo tempo sintetizar o pensamento europeu dos socialistas portugueses ao apresentar na campanha o modelo social europeu como um conceito estruturante e fundamental para e da União.

A "Europa social", a "ditadura do mercado" ou a "solidariedade europeia" são partes de uma retórica que aproximaria o PS de 2014 dos pais fundadores do socialismo democrático português, enquadraria na atualidade o pensamento político de Mário Soares, Almeida Santos e Manuel Alegre e encontraria nas outras gerações ativas do partido - de que António José Seguro, José Sócrates, Augusto Santos Silva, António Costa, Francisco Assis, Sérgio Sousa Pinto ou João Galamba, entre tantos outros, são legítimos representantes -, ainda que de sensibilidades internas distintas, posicionamentos de convergência e proximidade.

Entre o antieuropeísmo do Partido Comunista Português e o ceticismo de alguma direita mais conservadora, nacional e unitarista, o Partido Socialista procuraria aglutinar nas europeias de 2014 sensibilidades e tendências de opinião muito abrangentes, que iriam de defensores da "reestruturação da dívida" a setores da sociedade portuguesa que se consideram prejudicadas pelas opções orçamentais, financeiras e económicas do governo de Passos Coelho e Paulo Portas, quer à direita quer à esquerda ${ }^{3}$.

Por diversas razões, as eleições europeias de 2014 seriam de primordial importância para os socialistas portugueses. O papel reforçado do Banco Central Europeu e o reforço do investimento público, a discordância com Passos Coelho relativamente às políticas de austeridade - e ao mesmo tempo de apoio ao rigor orçamental e à consolidação das contas públicas -, nas políticas públicas de educação, ciência, investigação e saúde; as questões levantadas sobre as desigualdades sociais, a queda do investimento público e a "estratégia 20-20" da União Europeia são matérias

\footnotetext{
${ }^{3}$ Refira-se que foi também, entre outras razões, pelo facto de o PS ser um partido político de vocação europeísta que personalidades centristas ou da direita portuguesa como Freitas do Amaral, Basílio Horta ou Luís Barbosa, por exemplo, se aproximaram do seu arco de intervenção e ação política em fuga de um CDS que mudaria para PP e se afastaria do federalismo europeu aquando da liderança de Manuel Monteiro.
} 
que o Partido Socialista abordou na sua campanha eleitoral em confrontação direta com um executivo que consideraria "neoliberal repressivo e defensor do Estado-mínimo “.

Como estratégia, o Partido Socialista, na pessoa do candidato Francisco Assis, defenderia nas Europeias de 2014 o crescimento da economia e a criação de emprego e a compatibilização destas prioridades com o rigor das contas do Estado. Francisco Assis entenderia também que uma vitória para o partido seria simplesmente ter "mais votos do que a direita, nem que mais um", contando para isso com "uma lista de excelência contra a aliança da direita" - na qual constariam nomes como Maria João Rodrigues, Carlos Zorrinho, Elisa Ferreira, Ana Gomes ou Pedro Silva Pereira, entre outros - e sem definir a maioria absoluta como objetivo fundamental ou obrigatório para a estrutura partidária representativa do centro-esquerda. Para tal proporia que Portugal assumisse uma posição mais exigente relativamente ao diretório comunitário liderado pela Alemanha, o estabelecimento de alianças com os estados europeus num quadro de igualdade entre os mesmos e ainda uma outra política monetária. Contra o deflacionismo e o "discurso da inevitabilidade da direita", Francisco Assis referiria que o Parlamento Europeu é hoje mais forte do que há cinco anos, o que seria considerado positivo para o debate europeu.

Francisco Assis proporia ainda a mutualização parcial da divida portuguesa como os socialistas europeus de que o alemão Martins Schulz é um exemplo -, no quadro de uma união solidaria entre os estados europeus. Contra o que designa por "servilismo face à Alemanha", Francisco Assis contrariaria as opções da direita ao sustentar um outro papel para o BCE e apoiaria a intervenção e liderança de Mario Draghi, considerada "favorável ao Euro".

Contra uma Europa do sul e outra do norte, Francisco Assis afirmar-se-ia ainda contra a austeridade permanente defendendo que as preocupações com o crescimento económico deveriam acompanhar, ao mesmo tempo, as preocupações financeiras do país. Na voz do dirigente socialista Eurico Brilhante Dias, o Partido Socialista sustentaria e ratificaria o tratado orçamental mas num alcance de "médio prazo".

Os socialistas considerariam positivo para Portugal a existência de uma "saída limpa", sem programa cautelar e a "saída da troika do país". De qualquer das formas Francisco Assis e o Partido Socialista afirmar-se-iam contra "consensos com a direita" e ainda contra "uma cultura de compromisso" a que o Presidente da República havia apelado. Contra também as políticas que promovam a emigração portuguesa "jovem e qualificada" e em contraposição a uma "política de ordenados baixos", o Partido 
Socialista nestas eleições europeias defenderia uma Europa assente no conhecimento e em políticas de investimento em formação e educação que divergissem de opções que sustentassem uma economia assente em mão-de-obra barata; defenderia ainda uma "Europa dos cidadãos" - que Maurice Duverger teorizou na sua obra com o mesmo nome - e de "cooperação" e não de "subjugação dos mais fracos aos mais fortes".

Num quadro de défice e com uma dívida pública de aproximadamente 130 por cento do PIB em 2014 - quando era de 90 por cento em 2011 -, o Partido Socialista centrar-se-ia na "carta de intenções do FMI" - defendendo a sua divulgação pública - e criticaria o que considera ser a "austeridade expansionista do executivo", sustentado em contraponto a compatibilização da política monetária e fiscal com o rigor orçamental. Numa base Keynesiana, o Partido Socialista defenderia ainda a promoção de investimentos públicos controlados como uma forma de gerar desenvolvimento para o país. O debate ideológico com a direita de Passos Coelho far-se-ia também na base de conceitos clássicos defensores ou de mais intervencionismo estatal ou, por outro lado, de uma maior participação da sociedade civil na definição de propostas para o país já teorizadas, por exemplo, em iniciativas como o "Compromisso Portugal".

Partindo de considerações definidoras da Europa como "o maior projeto político do nosso tempo", Francisco Assis insistiria na qualificação das pessoas e no apoio à investigação científica como prioridades fundamentais do posicionamento dos socialistas europeus, ao mesmo tempo que sustentaria uma relação do Estado português com as instituições europeias diferente da atual - que classifica de obediência e não de igualdade -, propondo neste quadro que Portugal passe a estar na Europa em plenitude e em parceria com os outros estados-membros num contexto europeu de predominância dos "partidos da direita".

$\mathrm{Na}$ apresentação do manifesto eleitoral, que teria lugar na sede do Largo do Rato no dia 8 de Maio - com o título "Mudança: Mudar Portugal, Mudar a Europa" -, o PS procuraria fazer convergir num só ponto ou documento todas estas questões doutrinárias que referimos ao longo deste pequeno texto. Relativamente ao DEO - Documento de Estratégia Orçamental -, que prevê entre outras medidas a reposição gradual de 20 por cento ao ano dos salários dos funcionários públicos a partir de 2015 e até 2019, importa referir que seria apresentado na Assembleia da República, em Bruxelas e ao FMI e também, por outro lado, objeto por parte dos dirigentes do Partido Socialista de críticas uma vez que, sustentados no parecer do CES - Conselho Económico e Social -, considerariam as medidas definidas como "algo negativo para o país" nomeadamente os 
cortes nas pensões e o aumento de impostos, pois nesta perspetiva poderiam dar origem a uma "quebra de confiança entre o Estado e os cidadãos".

A ideia de uma cimeira da troika em Portugal no dia das eleições seria igualmente objeto de divergências por parte da esquerda, nomeadamente do Partido Socialista que antes preferiria fazer convergir os esforços dos seus dirigentes para os debates considerados estrategicamente prioritários como "o emprego, a união económica e monetária, a política do mar, as energias renováveis, a proteção social, a ciência e a tecnologia e os eurobonds" e ainda as questões em torno do fato de o Tratado da União Europeia proibir a assunção por parte de terceiros da dívida pública dos estados-membros e as matérias relacionadas com o "orçamento federal" e a "união bancária”. Estas seriam as questões fundamentais para o debate que os socialistas pretendiam desenvolver nestas eleições.

O Partido Socialista consideraria que a Europa caminhou no sentido da união monetária mas não da união económica e que a igualdade entre os estados-membros deveria constituir-se como um pilar efetivo e material da construção europeia e não apenas como uma linha programática de um cenário mais teórico. A liderança não inclusiva da Alemanha e da França - mais da Alemanha do que da França - seria considerada na campanha eleitoral por Francisco Assis como um sinal e uma prova do “esvaziamento da Comissão Europeia”, instituição a que compete fazer cumprir os tratados e os princípios da igualdade e da coesão económica que estão na base de objetivos comuns como o bem-estar social e o nivelamento por cima dos rendimentos dos europeus.

O "bailout" de Portugal, sem linha de crédito ou programa cautelar, seria considerado pelo Partido Socialista como uma questão positiva para o país. No entanto consideraria necessário também que a Europa caminhasse no sentido da criação de consensos entre sociais-democratas e democratas-cristãos no que concerne às questões essenciais do projeto de construção e em pontos tão estruturantes como, por exemplo, o papel do estado social e o futuro do modelo social europeu. Um contributo mais claro e uma atribuição mais ativa do BCE - que o Partido Socialista considera como algo que está implícito nos tratados - seria um ponto estruturante da retórica socialista nestas eleições. Ao contrário da política económica seguida pelos EUA em cenário de crise expansionista, de investimento em ativos e de apoio à economia -, o Partido Socialista consideraria que a Europa caminha para políticas económicas potenciadoras da 
"estagnação, desemprego e deflação", nomeadamente Portugal pela mão de Passos Coelho ${ }^{4}$.

É neste contexto que o BCE é mas uma vez referido e comparado com a reserva federal americana quando se considera o primeiro como "entidade que deveria controlar os bancos europeus" e o segundo como "promotor do crescimento e do desenvolvimento económicos". O aumento do fosso existente entre "ricos e pobres" e o "norte e sul" europeus é considerado neste quadro como o resultado de uma política europeia que deveria, isso sim, "recalibrar as políticas de rigor orçamental" no sentido de se caminhar para o controlo dos efeitos da austeridade na economia real da União, sobretudo dos estados que estão sob intervenção externa.

As comparações das políticas restritivas e de "cortes" de Passos Coelho com as seguidas por Hollande seriam entendidas por Francisco Assis como "infundadas" uma vez que entende e refere neste campo que a política do governo francês é diferente da portuguesa quando opta por "cortes nominais e não reais". Francisco Assis preferiria referir que o PSD não cortou nas "gorduras do Estado", como sublinhou em campanha, "preferindo centrar-se nos rendimentos das pessoas". O aumento da TSU foi apontado neste seguimento como um exemplo da diminuição destes rendimentos e o DEO como prova dessas opções governamentais já que o mesmo, segundo o dirigente socialista, "aumenta de forma significativa os impostos e corta nos salários".

Para José Sócrates, antigo Primeiro-ministro e ator central da história recente dos socialistas, por causa da ação do governo de Passos Coelho, o PIB per capita "recuou vinte anos", os rendimentos e as desigualdades voltaram aos números de "há oito anos", a dívida pública aumentou e o investimento e os resultados da economia "regrediriam vinte anos". O "semestre europeu", o crescimento anémico da economia portuguesa previsto para os próximos 24 anos - por causa do pagamento de 3 por cento ao ano de juros da dívida - e os "choques assimétricos nos países periféricos" seriam questões referidas no debate entre candidatos socialistas e sociais-democratas nestas eleições europeias, que contribuiriam na campanha para a definição ideológica da direita e da esquerda moderadas, questão que a Coligação Democrática Unitária aflorou no terreno ideológico ao considerar que os partidos do centro "não têm diferenças significativas".

\footnotetext{
${ }^{4} \mathrm{O}$ recurso a comparações com os EUA, nomeadamente quando se fala do Tribunal Constitucional, seria uma prática recorrente do PSD a que o PS procuraria responder com outras realidades americanas e comparações sobretudo ao nível de matérias económicas e de soberania.
} 
Depois de completar 41 anos de existência no dia 19 de Abril de 2014, o Partido Socialista insistiria em temas - também para justificar as suas diferenças com o PSD como o estado social, a escola pública, o serviço nacional de saúde e a segurança social como baluartes ou bastiões da sua doutrina e dos seus conceitos. Contra uma direita que considera "ultraliberal e ultraconservadora", o Partido Socialista revisitaria nas suas comemorações em Ourém o slogan "Europa Connosco" no sentido de - na presença do dirigente social-democrata alemão Sigmar Gabriel - referir e sublinhar a "necessidade de se caminhar para uma Europa não assente apenas em políticas de austeridade", que, para António Vitorino, "agravam o risco de pobreza".

O Partido Socialista preferiria referir a necessidade de se assegurar um mecanismo de mutualização de garantias a nível europeu ao mesmo tempo que procuraria contrariar um "governo português mais troikista do que a troika" e que "negoceia nas costas dos portugueses mais cortes". Neste seguimento o regresso de José Sócrates, na campanha eleitoral e ao lado de Francisco Assis, ao enquadramento político-partidário seria salientado e interpretado por Paulo Portas, Vice-Primeiroministro, como “o regresso do responsável pela situação de emergência nacional”.

\section{Depois das Europeias de 2014}

Num quadro eleitoral europeu negativo para os socialistas, quer em Espanha quer em França, o Partido Socialista em Portugal acabaria por vencer por uma margem próxima dos 5 por cento ${ }^{5}$. Com 31,4 por cento dos votos - quando havia ainda 4 deputados por apurar e 15 consulados -, os socialistas elegeriam no total 8 deputados ao Parlamento Europeu num leque de 21 possíveis, superando em quase 6 pontos os resultados de 2009. Estes resultados, considerados como uma pequena vitória por Mário Soares, dariam origem à candidatura de António Costa à liderança do PS e constituem uma possibilidade para o PS mudar de estratégias, lideranças e retóricas. Os resultados garantiram a vitória socialista mas uma vez que estas eleições foram interpretadas como uma antecâmara das legislativas de 2015 os mesmos não iriam de encontro às expectativas de parte significativa de simpatizantes, eleitores, aderentes, militantes e

\footnotetext{
${ }^{5}$ Devemos referir que é certo que os partidos socialistas europeus sofreram uma derrota generalizada nas Europeias de 2014 e que o PS venceria as eleições em Portugal. De qualquer das formas, nenhum país - à exceção da Grécia - sofreria uma intervenção externa da dimensão da portuguesa. Isto significa que a vitória dos socialistas poderá ser enquadrada também num quadro penalizador do governo e não apenas num contexto meritório das suas propostas ou lideranças.
} 
dirigentes do PS. Como se observa no Quadro 2, a Aliança Portugal, constituída pelos partidos da direita parlamentar PPD/PSD e CDS/PP, elegeria 7 deputados e acabaria por alcançar perto de 27,7 por cento dos votos num quadro que compreendeu uma abstenção superior aos 64 por cento.

Quadro 2: Deputados ao PE (2014)

\begin{tabular}{|c|c|c|c|}
\hline Ano & $\begin{array}{c}\text { Total } \\
\text { Deputados }\end{array}$ & PS & PSD/CDS \\
\hline 2014 & 21 & 8 & 7 \\
\hline
\end{tabular}

Fonte: PORDATA

Refira-se que, se na França, Dinamarca e Inglaterra as extremas-direitas e as forças nacionalistas tiveram votações expressivas - e na Grécia a esquerda radical -, em Portugal o Movimento Partido da Terra e Marinho e Pinto seriam os atores que mais votos retirariam aos socialistas e à direita "do arco da governabilidade". Como consequência imediata destes resultados António Costa avançaria para a liderança do partido indo assim ao encontro de sensibilidades como Vera Jardim, Vítor Ramalho ou Mário Soares que criticariam os parcos resultados de António José Seguro. O cenário mediático pós-eleitoral, "de agenda", compreenderia sobretudo as decisões pendentes do Tribunal Constitucional bem como os "chumbos" a mais cortes, o designado "Manifesto dos 74", a revisão dos critérios centrais/fundamentais do tratado orçamental, a política de possíveis coligações pós-eleitorais à esquerda e à direita em 2015, as reflexões em torno das lideranças partidárias de António José Seguro, de Passos Coelho e de Paulo Portas, o papel e a magistratura do Presidente da República, as pressões das oposições em defesa de eleições antecipadas, o comportamento dos mercados e dos juros, a segurança europeia, a reforma do Estado, a reforma fiscal, os critérios de aplicação dos fundos europeus, a criação ou não de um plano Marshall para os países da periferia europeia e a gestão sindical e patronal das questões relacionadas com o salário mínimo e a contratação coletiva em sede de concertação social.

Esta "agenda" mediática seria particularmente relevante para o Partido Socialista uma vez que o partido estaria sobretudo centrado na disputa interna que António Costa espoletaria pela liderança que sublinhámos. Depois das eleições europeias o PS seria confrontado com uma divisão interna e duas visões e estratégias para o futuro. António Costa e António José Seguro são candidatos a Primeiro-ministro, a secretário-geral e a líder dos socialistas mas une-os a mesma ideia de Europa, o modelo social europeu e a 
ideia original desenhada no "a Europa Connosco". No quadro deste artigo o que relevamos é sobretudo a ideia de continuidade e testemunho que as diversas gerações de socialistas imprimiram relativamente aos grandes temas europeus. Relativamente às eleições europeias refira-se portanto que seriam eleitos como deputados ao parlamento os socialistas Francisco Assis, Maria João Rodrigues, Carlos Zorrinho, Elisa Ferreira, Ricardo Santos, Ana Gomes, Pedro Silva Pereira e Liliana Rodrigues.

No essencial referimos que o Partido Socialista, enquanto partido de vocação governamental, procurou nestas eleições de 2014 um resultado que o projetasse como alternativa indiscutível ao governo liberal de Passos Coelho. Mesmo tendo alcançado mais votos do que a Aliança Portugal - como referiu Francisco Assis até uma vantagem por um voto seria importante para o partido -, o PS não atingiria os valores históricos que alguns observadores projetariam. A sua vitória foi escassa e por isso encontra-se na altura em que este texto foi escrito - num cenário de luta interna pela liderança entre António José Seguro e António Costa. O que distingue os dois atores socialistas não é certamente a política ou a doutrina europeias. No que concerne ao objeto deste texto, as matérias europeias não dividem o Partido Socialista. Os afastamentos e os antagonismos estarão relacionados neste caso com o "estilo" e a "vocação" de cada um dos dirigentes.

No que se refere à Europa, o PS continua unido nas questões fundamentais relacionadas com o modelo social, o Estado social e a igualdade de princípio entre os estados que compõem o arco europeu, dentro ou fora da "zona euro". Ao contrário do CDS/PP, por exemplo, a Europa não é e nunca foi uma questão de divisão interna do PS. Princípios como a cooperação com a Europa na gestão dos ciclos, políticos e económicos e a não transformação do Tratado Orçamental num mero exercício contabilístico são duas das questões que distinguem uma visão socialista de um ponto de vista mais próximo do executivo de Passos Coelho. E neste ponto não se observa nenhuma tendência desviante no seio dos socialistas.

As questões centradas no combate ao desemprego bem como nos desequilíbrios da zona euro são, em síntese, duas das matérias nucleares do combate político à esquerda que o Partido Socialista protagoniza em Portugal e na Europa. Nestas linhas referimos que o Partido Socialista, ao contrário de algumas perspetivas mais à esquerda, parece procurar distinguir-se da direita parlamentar nos assuntos europeus defendendo um Tratado Orçamental que se dirija ao investimento na economia e no sentido da qualificação. Diríamos que, ao contrário do contabilismo e da frieza dos números da direita política, a esquerda socialista procura alguma orientação e algum sentido 
estratégico e de futuro na política de cortes e poupanças a que a atual crise obriga. Para Carlos Zorrinho, por exemplo, “o equilíbrio das contas públicas só não é aceitável se for conseguido à conta do empobrecimento, da asfixia da economia e da captura dos estados pelos interesses imediatos dos credores"6. Neste enquadramento o Partido Socialista propõe o aprofundamento da União Económica e Monetária e a criação de instrumentos que impeçam a Europa e os estados-membros de colapsar.

$\mathrm{O}$ apoio às PME surge neste ideário e neste panorama como uma das estratégias a seguir não só no quadro do combate ao desemprego jovem - e não só jovem - mas também como fundamento de uma maior dinamização da economia europeia. Estas ideias, aliás, são subscritas por Martin Schulz e pela família da esquerda democrática de matriz europeia a que o Partido Socialista pertence.

Entre António Costa e António José Seguro sobrarão as divergências estratégicas, táticas e "de estilo" no quadro da corrida à liderança da Secretaria-geral do Partido Socialista. No que concerne à temática europeia as convergências são de fundo e o patriotismo luso-europeu do PS surge estruturado. Se falarmos de construção europeia, de eleições e conceitos europeus o partido de Mário Soares e de Manuel Alegre manteve ao longo de todo o seu percurso um só rumo, uma só definição ideológica e um só posicionamento central face aos desafios dos tratados da construção.

O Partido Socialista, nesta problemática, define-se quer no quadro do costismo quer do segurismo em 2014 como um partido francamente europeísta na esteira dos pais fundadores da Europa, dos fundamentos do próprio partido e da família europeia a que aderiu, como em 1986 aquando da oficialização da entrada de Portugal na CEE pelas mãos de Mário Soares e Medeiros Ferreira ${ }^{7}$. Em 1977 - e que melhor contributo poderiam democratas-cristãos e socialistas dar ao país, segundo Adelino Amaro da Costa -, depois da formalização do pedido português de adesão ao Mercado Comum levado a cabo por Mário Soares e Medeiros Ferreira, o PS assistiria por parte do CDS a uma certa competição pela liderança do processo que conduziria à adesão de Portugal à

\footnotetext{
${ }^{6}$ Ação Socialista n ${ }^{\circ} 1387$ de Maio de 2014, p.7. Carlos Zorrinho, apoiante de António José Seguro na luta interna pela liderança do partido, seria eleito deputado ao Parlamento Europeu criticando a matriz mais financeira do que social do processo de construção liderado pela Alemanha.

${ }^{7}$ José Medeiros Ferreira, um dos mais ilustres pensadores socialistas no que concerne ao processo de construção da Europa - de uma Europa à imagem dos pais fundadores -, enquanto quadro partidário mas sobretudo enquanto investigador e académico, marcaria um dos períodos mais relevantes da democracia portuguesa nomeadamente o que levou à consumação da adesão de Portugal às Comunidades. Do ponto de vista da conceção, do desenho e da definição do pensamento europeu do Partido Socialista nessa época Medeiros Ferreira afirmar-se-ia como uma personalidade de destacada intervenção, que não poderíamos deixar de referir quando se falamos de Europa e do PS.
} 
$\mathrm{CEE}^{8}$. De qualquer das formas seria no período do Bloco Central - com o PS na chefia do governo - que Portugal entraria nas Comunidades e começaria a sua integração na Europa.

Nestas eleições europeias o PS usou os meios financeiros, logísticos e humanos que constituem o seu aparelho militante com o propósito de eleger o maior número possível de deputados ao Parlamento Europeu. O objetivo era vencer as eleições europeias mas também preparar as condições para a formação de um governo francamente maioritário em 2015. Uma vez que a vitória eleitoral não se consubstanciou numa maioria significativa, poderemos estar a assistir à emergência de uma liderança que, mantendo o fundamental das perspetivas europeias do PS, pretenderá a partir de setembro de 2014 alcançar condições para a construção de uma superioridade eleitoral robusta relativamente aos partidos da direita parlamentar. No fundamental uma maioria que, também nas questões europeias, mantenha bem vivo o sonho dos homens que fundaram e desenharam o PS em 1973 em terras alemãs.

\section{Bibliografia}

AMARAL, Diogo Freitas do - O Antigo Regime e a Revolução: memórias políticas (1941-1975). Lisboa: Bertrand, 1995.

DUVERGER, Maurice - A Europa dos Cidadãos. Lisboa: Asa, 1994.

FERNANDES, António José - Ciência Política. Lisboa: Escola Superior de Polícia, 1991.

FREDERICO, Rui Madeira - Evolução político-ideológica do CDS/PP. In A Reforma do Estado em Portugal: Problemas e Perspetivas (Atas do I Encontro Nacional de Ciência Política). Lisboa: Bizâncio, 1999, pp. 385-414.

INE - Portugal: 20 Anos de Integração Europeia. Lisboa: INE, 2007.

\footnotetext{
${ }^{8}$ Com vista à preparação do fresco de alargamento da Europa a Portugal, o CDS e o PS encetariam um conjunto de contatos com os seus congéneres no sentido de granjear apoio e também influenciar o caráter positivo do parecer da Comissão à adesão do país às Comunidades (In FREDERICO, Rui Madeira Evolução político-ideológica do CDS/PP. In A Reforma do Estado em Portugal: Problemas e Perspetivas (Atas do I Encontro Nacional de Ciência Política). Lisboa: Bizâncio, 1999, pp. 386-387).
} 
PS - Manifesto Eleitoral às Eleições Europeias de 2014. Mudança: Mudar Portugal, Mudar a Europa, Lisboa: PS, 2014.

SEBASTIÃO, Dina - Mário Soares e a Europa: Pensamento e Acção, dissertação de mestrado em História Contemporânea: economia, sociedade e relações internacionais. Coimbra: Universidade de Coimbra, 2010.

SOARES, Mário - Português e Europeu. Lisboa: Círculo de Leitores, 2000.

SOARES, Mário e PINTO, Sérgio Sousa - Diálogo de Gerações. Lisboa: Círculo de Leitores, 2003.

Outras Referências

Ação Socialista $\mathrm{n}^{\mathrm{o}} 1386$ de Abril de 2014.

Ação Socialista $\mathrm{n}^{\circ} 1387$ de Maio de 2014.

Correio da Manhã de 26 de Maio de 2014, pp. 3-6.

www.pordata.pt

www.pseuropeias2014.pt

www.ps.pt/noticias 